\title{
Intracranial stimulation of the trigeminal nerve in man I. Direct motor responses
}

\author{
GIORGIO CRUCCU \\ From the Pain Relief Foundation and Department of Neurosciences, Walton Hospital, Liverpool, UK
}

SUMMARY Direct electrical stimulation of the intracranial portion of the trigeminal nerve was performed in 23 subjects undergoing retrogasserian thermocoagulation for the treatment of idiopathic trigeminal neuralgia. In 16 subjects, who were having the operation for the first time, neurological examination was normal, as was neurophysiological testing of trigeminal function. Seven subjects were being operated for the second time, owing to a recurrence of symptoms. In all the subjects being operated for the first time, direct motor responses were obtained from ipsilateral temporalis, masseter and anterior belly of the digastric. The motor conduction velocity was equal for the fibres directed to all three muscles. This was estimated to be $54 \mathrm{~m} / \mathrm{s}$ in the masseteric nerve and $55-68 \mathrm{~m} / \mathrm{s}$ in the intracranial portion of the trigeminal nerve. Patients who had undergone previous thermocoagulation had a considerably slower conduction velocity. It is supposed that myelin sheaths had been damaged at the first operation.

The trigeminal nerve is a mixed nerve subserving sensation of the face and the muscles of mastication. The motor and sensory fibres, however, run in separate nerves for most of their course, partially merging only in the retrogasserian rootlets and in a short portion of the mandibular nerve. ${ }^{1}$ While the cutaneous nerves, through the supraorbital, infraorbital and mental foramina, emerge on the surface of the face, the motor nerves lie in the depth of the facial structures and their terminal branches enter the muscle bellies on their deep surface. This makes the stimulation of trigeminal efferent and afferent alpha fibres difficult. When compared with the main limb nerves, electrophysiology has provided little information about the human trigeminal nerve. The conduction velocity of the motor fibres and the afferent sensory fibre groups have not been directly measured, the cortical evoked potentials are far from being certainly identified ${ }^{23}$ and even the more widely used trigeminal reflexes are obscure in many details. ${ }^{45}$

The operation of percutaneous trigeminal rhizotomy provides a unique opportunity to reach the intracranial portion of the trigeminal nerve and to

Present address and address for reprint requests: Dr G Cruccu, Dipartimento Neuroscienze, Universita' di Roma, Viale Universita', 30, 00185 Roma, Italy.

Received 12 April 1985 and in revised form 25 June 1985. Accepted 27 June 1985 stimulate motor and sensory fibres, thus allowing the recording of both direct and reflex responses. This paper describes the motor responses in the masticatory muscles from stimulation of the retrogasserian rootlets and the mandibular nerve, in subjects without neurological defects who were having the operation for the first time, and in subjects who had been already submitted to a surgical retrogasserian lesion, either by "controlled differential thermocoagulation" 7 or by "partial root section". 89 Both techniques are supposed to spare the motor fibres.

\section{Methods}

The study has been carried out in 23 subjects, who gave informed consent, undergoing retrogasserian rhizotomy by radiofrequency thermocoagulation ${ }^{6}$ for the treatment of idiopathic neuralgia in the third (V3) or second (V2) division. There were 11 men and 12 women. The right side of the face was affected in 14 cases and the left in nine cases.

Sixteen cases were diagnosed as idiopathic trigeminal neuralgia, eight in V3 and eight in V2. Their ages ranged from 43 to 67 years, the mean age being 56 years. These subjects were selected among those without abnormal neurological or electrodiagnostic findings using known electrophysiological techniques: blink reflex and jaw jerk, masticatory EMG. ${ }^{10-14}$ In particular, the supraorbital nerve was stimulated transcutaneously at the supraorbital groove and the infraorbital nerve via a pair of fine needle-electrodes inserted into the homonymous foramen. In both cases the right and left side were stimulated with square wave $0 \cdot 1-0 \cdot 3$ $\mathrm{ms}$ pulses of adequate intensity and surface recordings were 
Table 1 Direct responses in the masticatory muscles (mean \pm standard deviation of negative components)

\begin{tabular}{|c|c|c|c|c|c|c|c|c|c|}
\hline & \multicolumn{3}{|l|}{ Masseter } & \multicolumn{3}{|c|}{ Temporalis } & \multicolumn{3}{|l|}{ Digastric } \\
\hline & $\begin{array}{l}\text { Onset } \\
\text { latency } \\
(\mathrm{ms})\end{array}$ & $\begin{array}{l}\text { Amplitude } \\
(\mu V)\end{array}$ & $\begin{array}{l}\text { Duration } \\
\text { (ms) }\end{array}$ & $\begin{array}{l}\text { Onset } \\
\text { latency } \\
\text { (ms) }\end{array}$ & $\begin{array}{l}\text { Amplitude } \\
(\mu V)\end{array}$ & $\begin{array}{l}\text { Duration } \\
\text { (ms) }\end{array}$ & $\begin{array}{l}\text { Onset } \\
\text { latency } \\
\text { (ms) }\end{array}$ & $\begin{array}{l}\text { Amplitude } \\
(\mu V)\end{array}$ & $\begin{array}{l}\text { Duration } \\
\text { (ms) }\end{array}$ \\
\hline $\begin{array}{l}\text { Stimulation at } \\
\text { foramen ovale } \\
\text { (16 subjects) }\end{array}$ & $\begin{aligned} & 2 \cdot 2 \\
\pm & 0 \cdot 19\end{aligned}$ & $\begin{array}{r}3100 \\
\pm 2300\end{array}$ & $\begin{array}{r}3.9 \\
\pm 0.7\end{array}$ & $\begin{array}{c}2 \cdot 2 \\
\pm 0 \cdot 36\end{array}$ & $\begin{array}{r}4300 \\
\pm 4000\end{array}$ & $\begin{array}{r}5.3 \\
\pm 0.9\end{array}$ & $\begin{array}{r}2.94 \\
\pm 0.33\end{array}$ & $\begin{array}{r}4400 \\
\pm 3700\end{array}$ & $\begin{array}{r}4 \cdot 3 \\
\pm 0.5\end{array}$ \\
\hline $\begin{array}{l}\text { Stimulation at } \\
\text { clivus } \\
\text { (paired differences } \\
\text { with }\end{array}$ & $\begin{array}{l}+0 \cdot 26 \\
\pm 0 \cdot 14\end{array}$ & $\begin{array}{r}-900 \\
\pm 1800\end{array}$ & $\begin{array}{c}0.1 \\
\pm 0.12\end{array}$ & $\begin{array}{r}0.25 \\
\pm 0.19\end{array}$ & $\begin{array}{l}-1200 \\
\pm 3000\end{array}$ & $\begin{array}{l}+0.14 \\
\pm 0.44\end{array}$ & $\begin{array}{l}+0.24 \\
\pm 0.09\end{array}$ & $\begin{array}{l}-1100 \\
\pm 2000\end{array}$ & $\begin{array}{l}+0.03 \\
\pm 0.23\end{array}$ \\
\hline $\begin{array}{l}\text { foramen ovale in } \\
8 \mathrm{~V} 3 \text { subjects) }\end{array}$ & $p<0.01$ & NS & $p<0.05$ & $p<0.01$ & NS & NS & $p<0.01$ & NS & NS \\
\hline $\begin{array}{l}\text { Stimulation at } \\
\text { zygomatic arch } \\
\text { (paired differences } \\
\text { with }\end{array}$ & $\begin{array}{l}-0.55 \\
\pm 0.21\end{array}$ & $\begin{array}{l}+1200 \\
\pm 1500\end{array}$ & $\begin{array}{l}-0.5 \\
\pm 0.6\end{array}$ & & & & & & \\
\hline $\begin{array}{l}\text { foramen ovale in } \\
8 \mathrm{~V} 3 \text { subjects) }\end{array}$ & $p<0.01$ & NS & $p<0.05$ & & & & & & \\
\hline
\end{tabular}

taken from the inferior orbicularis oculi muscle bilaterally. The jaw jerk was evoked by tapping the chin with a triggered hammer and recorded from the masseter and temporal muscles bilaterally.

Seven cases had previously undergone an operation for the treatment of facial pain which had been diagnosed as idiopathic trigeminal neuralgia (table 2). Five cases were having the same operation, that is radiofrequency thermocoagulation, for the second time, and two cases had had surgical partial section of the root. In two cases there had been no pain relief and in the others the neuralgia had recurred. All presented with sensory deficits to a variable extent or neurophysiological abnormalities. Most patients were receiving anticonvulsants (mainly carbamazepine) up to 24 hours before surgery. During the operation the subjects were fully conscious, while they were always fully anaesthetised during the coagulation, by means of a short-acting barbiturate (methohexitone IV).
The percutaneous method employed for the lesion of the sensory root has been described in detail by several authors. ${ }^{6715}$ The ganglion was approached by passing a cannula through the foramen ovale, guided by means of $x$ rays and image intensification with a TV monitor. The intraoperative recordings were first performed when radiographs in lateral projection showed that the tip of the cannula had reached the foramen ovale and then when the level of the clivus was attained. In the first position the needle was presumed to be in the mandibular nerve just distal to the ganglion, and in the second within the trigeminal root. ${ }^{17}$ The stimulating electrode consisted of an insulated stylet with a bare tip of $2 \mathrm{~mm}$ which protruded by $1 \mathrm{~mm}$ from the teflon-coated surgical needle, whose tip was bared for $5 \mathrm{~mm}$. The stylet was connected to the cathode and the cannula to the anode of the stimulator. Square-wave negative pulses (0.5-50 $\mathrm{mA}, 0.1-0.5 \mathrm{~ms})$ were delivered manually at a low rate or repetitively at $1 \mathrm{~Hz}$.

Table 2 Masseter responses in re-operated subjects

\begin{tabular}{|c|c|c|c|c|c|c|c|}
\hline $\begin{array}{l}\text { Case, sex } \\
\text { \&age (yr) }\end{array}$ & $\begin{array}{l}\text { Previous } \\
\text { operation }\end{array}$ & $\begin{array}{l}M \text {-wave } \\
\text { latency }\end{array}$ & $\begin{array}{l}\text { M-wave } \\
\text { amplitude }\end{array}$ & $\begin{array}{l}\text { Intracranial } \\
\text { velocity }\end{array}$ & $\begin{array}{l}\text { Jaw } \\
\text { reflex }\end{array}$ & $\begin{array}{l}\text { Clinical-EMG } \\
\text { function }\end{array}$ & Comment \\
\hline $\begin{array}{l}\text { Case } 4 \\
\text { F } 61\end{array}$ & $\begin{array}{l}\text { Thermocoagulation } \\
\text { for left V2 } \\
2 \text { years before }\end{array}$ & $\begin{array}{l}2.9 \mathrm{~ms} \\
\text { (abnormal) }\end{array}$ & $2 \cdot 1 \mathrm{mV}$ & $\begin{array}{l}28-34 \mathrm{~m} / \mathrm{s} \\
\text { (abnormal) }\end{array}$ & Delayed & Normal & Demyelination \\
\hline $\begin{array}{l}\text { Case } 5 \\
\text { M } 63\end{array}$ & $\begin{array}{l}\text { Thermocoagulation } \\
\text { for right V2-V3 } \\
3 \text { months before }\end{array}$ & $2 \cdot 2 \mathrm{~ms}$ & $\begin{array}{l}0.3 \mathrm{mV} \\
\text { (abnormal) }\end{array}$ & $\begin{array}{l}35-40 \mathrm{~m} / \mathrm{s} \\
\text { (abnormal) }\end{array}$ & Absent & Abnormal & $\begin{array}{c}\text { Demyelination } \\
\text { \& fibre loss }\end{array}$ \\
\hline $\begin{array}{l}\text { Case } 11 \\
\text { M } 68\end{array}$ & $\begin{array}{l}\text { Thermocoagulation } \\
\text { for left V3 } \\
10 \text { months before }\end{array}$ & $2 \cdot 1 \mathrm{~ms}$ & $1.2 \mathrm{mV}$ & $60-73 \mathrm{~m} / \mathrm{s}$ & Normal & Normal & Normal \\
\hline $\begin{array}{l}\text { Case } 13 \\
\text { F } 46\end{array}$ & $\begin{array}{l}\text { Thermocoagulation } \\
\text { for right V3 } \\
1 \text { month before }\end{array}$ & $2.4 \mathrm{~ms}$ & $2 \cdot 2 \mathrm{mV}$ & $\begin{array}{l}30-32 \mathrm{~m} / \mathrm{s} \\
\text { (abnormal) }\end{array}$ & Delayed & Normal & Demyelination \\
\hline $\begin{array}{l}\text { Case } 14 \\
\text { M 78 }\end{array}$ & $\begin{array}{l}\text { Partial right } \\
\text { root section } \\
20 \text { years before }\end{array}$ & Absent & Absent & Non evaluable & Absent & Abnormal & $\begin{array}{l}\text { Massive fibre } \\
\text { loss }\end{array}$ \\
\hline $\begin{array}{l}\text { Case } 19 \\
\text { F } 66\end{array}$ & $\begin{array}{l}\text { Partial left } \\
\text { root section } \\
12 \text { years before }\end{array}$ & $2 \cdot 2 \mathrm{~ms}$ & $1.8 \mathrm{mV}$ & $48-56 \mathrm{~m} / \mathrm{s}$ & Normal & Normal & Normal \\
\hline $\begin{array}{l}\text { Case } 22 \\
\text { M 70 }\end{array}$ & $\begin{array}{l}\text { Thermocoagulation } \\
\text { for left V } 2 \\
5 \text { years before }\end{array}$ & $\begin{array}{l}2 \cdot 6 \mathrm{~ms} \\
\text { (borderline) }\end{array}$ & $2.4 \mathrm{mV}$ & $\begin{array}{l}40-49 \mathrm{~m} / \mathrm{s} \\
\text { (borderline) }\end{array}$ & Normal & Normal & Doubtful \\
\hline
\end{tabular}


Signals were recorded by surface electrodes from the ipsilateral temporal, masseter and anterior belly of the digastric muscles, and by needle-electrodes from the orbicularis oculi. In the first cases, recording from the contralateral facial and masticatory muscles was also performed, as well as recordings by concentric EMG needles inserted into the muscle bellies. Signals were amplified, filtered $(8-3200 \mathrm{~Hz})$ and displayed by means of standard electromyography, and recorded on tape. Off-line processing included rectification and averaging when adequate, $A / D$ conversion and storage on floppy-disks for computer analysis. Statistical significance was evaluated with the Student's $t$ test.

The day after the operation, eight cases were submitted to stimulation of the masseteric nerve by means of two fine needles inserted immediately below the zygomatic arch and just anterior to the T-M joint to a depth of $10-15 \mathrm{~mm}$, according to the technique described by Godaux and Desmedt. ${ }^{16}$ By measurements on skulls and a topographic atlas, ${ }^{17}$ this position was evaluated to be $30 \mathrm{~mm}$ from the foramen ovale and $40 \mathrm{~mm}$ from the masseter motor point in the lower third of the muscle; the overall distance from the foramen ovale was approximately $70 \mathrm{~mm}$ to the masseter and temporalis and $112 \mathrm{~mm}$ to the anterior belly of the digastric.

\section{Results}

\section{Neurophysiological testing of trigeminal function}

The three trigeminal divisions were investigated by means of the blink reflex to supraorbital stimulation (V1), the blink reflex to infraorbital stimulation (V2) and the jaw jerk to taps to the chin (V3).

Latency, duration and amplitude of all reflexes fell in the normal range. ${ }^{5111318}$ However, because of the relatively wide interindividual range of normal values, the intraindividual latency difference between the right and left side was taken as a further discriminant for all reflexes. Latency differences of more than $1.2 \mathrm{~ms}, 8 \mathrm{~ms}$ and $0.5 \mathrm{~ms}$, for the early and late components of the blink reflex and for the jaw jerk respectively, were considered to be pathological findings. Three subjects had at least one delayed response on the same side as the neuralgia and consequently did not enter the study. Among the 16 selected cases, the early component of the blink reflex to infraorbital stimulation was bilaterally absent in four, while the late component and supraorbital blink were normal. This was not considered as a sign of trigeminal malfunctioning, since it occurs in a large proportion of normal subjects. ${ }^{18}$

\section{Responses to mandibular nerve stimulation}

When stimulating the mandibular nerve at the level of the foramen ovale, direct motor responses (M-waves) were readily obtained from the ipsilateral temporal, masseter and anterior belly of the digastric muscle, in all the 16 subjects with no neurological abnormalities (fig 1). Concentric needle recordings demonstrated that the potentials actually originated in these muscles. The current threshold was 0.5-4 mA, without significant differences among the three muscles. Responses of maximum voltage, starting with a negative component were recorded with the electrode disposition shown in fig 1 . The average features of the $M$ waves to supramaximal stimulation are given in table 1. The onset latency showed little inter-subjects variation and was the same for the temporal and masseter muscles, $2 \cdot 2 \mathrm{~ms}$. The latency to the digastric was longer, $2.9 \mathrm{~ms}$, and the difference $(0.72 \pm 0.23 \mathrm{SD})$ was statistically significant $(p<0.001)$.

The negative component of the temporalis $\mathbf{M}$-wave was longer in duration and usually bifid (fig 1). This was possibly due to the anatomical features of the muscle itself, which is divided into anterior and posterior portions and is peripherally innervated by three separate nerve branches. ${ }^{19}$

Mylohyoid contraction could correspond to the Mwave recorded via surface electrodes overlying the digastric but its direct activation was not proved owing to its thin and expanded shape which made it difficult to determine the correct positioning of a concentric needle.

The facial muscles and the contralateral masticatory muscles were not directly activated. A small amplitude potential, with onset latency of 3-4 ms and peak latency of 5-6 ms, usually preceded the ipsilateral orbicularis oculi reflex, ${ }^{20}$ though it was absent in the recordings via concentric needle, as if originating elsewhere than the orbicularis oculi. No movement of the eye-ball was clinically detected. Potentials with similar features could be picked up by surface electrodes or non insulated needles also from the contralateral facial and masticatory muscles (fig 2). It was possible to exclude a reflex origin for these potentials,

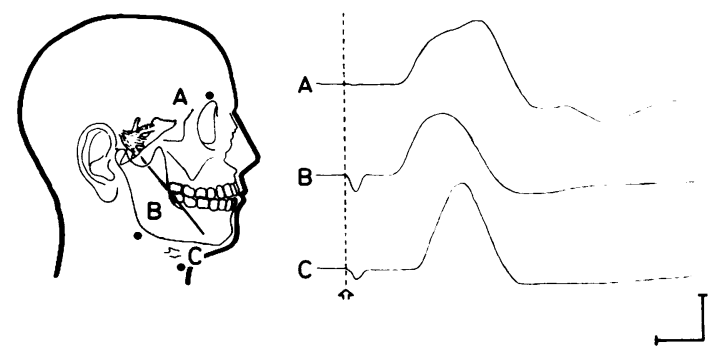

Fig 1 Direct motor responses from stimulation of the mandibular nerve. Left: schematic drawing showing disposition of the stimulating and recording electrodes; letters indicate active recording electrodes; black dots indicate reference electrodes. Right: temporal $(A)$, masseter $(B)$ and digastric (C) $M$-waves. Arrow indicates stimulus onset. Calibration: $2 \mathrm{~ms}, 2 \mathrm{mV}$. 
since their latency and morphology were quite stable. Moreover, when the stimulating electrode was pushed centralward in the retrogasserian position, the latency of these early waves, if still present, was slightly longer as if the distance had increased, which would be the case for a direct response. Since the potential was always accompanied by the presence of $\mathbf{M}$-waves in the ipsilateral masticatory muscles, it was thought to be a far-field potential from some masticatory muscle.

\section{Responses to retrogasserian stimulation}

When stimulating the trigeminal rootlets at the level of the clivus, the elicitation of $\mathbf{M}$-waves required higher stimulus intensities in general and also depended on whether the tip of the electrode was closer to the third or the second division. The masticatory muscles were activated in all eight cases undergoing a lesion of $\mathrm{V} 3$, at a current threshold of 1.5-7 mA.

In three out of the eight subjects undergoing a lesion of $\mathrm{V} 2$, no direct motor responses were obtained with stimuli up to $50 \mathrm{~mA}$. In the others high stimulus intensities were required: 5-20 mA. In two cases the $\mathrm{M}$-waves were far smaller than the respective responses elicited from the mandibular nerve, as if only some of the relevant motor nerve fibres had been activated.

When high intensity stimuli evoked painful sensations, supramaximal responses were recorded just before the coagulation, when the patient was anaesthetised.

Latencies to retrogasserian stimulation were always longer, to a small but very constant extent, than to foramen ovale stimulation. In the eight cases with V3 stimulation, the average latency difference was $0 \cdot 25 \mathrm{~ms} \pm 0 \cdot 19 \mathrm{SD}$ for the temporal, $0 \cdot 26 \pm 0 \cdot 14 \mathrm{SD}$
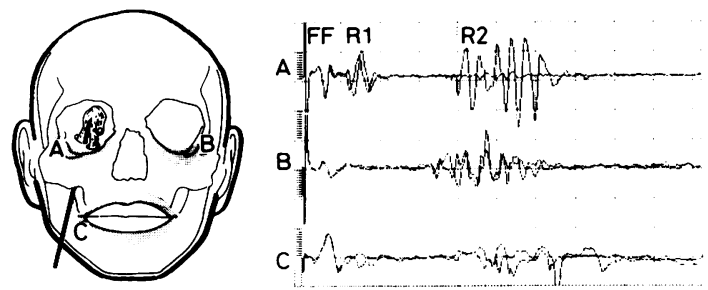

Fig 2 Recordings from facial muscles. (A) ipsilateral orbicularis oculi. (B) contralateral orbicularis oculi. (C) ipsilateral orbicularis oris.

Retrogasserian V2 stimulation.

Two successive sweeps are superimposed.

Calibration: $8 \mathrm{~ms} /$ div, $0 \cdot 2 \mathrm{mV} /$ div.

Early far-field potentials (FF), R1-and R2-like responses can be easily identified. Note that early potentials are stable in all derivations; $R 1$-like response is present only in the ipsilateral orbicularis oculi and shows a small jitter; R2-like responses are even more unstable. for the masseter and $0.24 \pm 0.09$ SD for the digastric responses (table 1). The average depth of the tip of the cannula, as measured from the surface of the skin, was $65 \mathrm{~mm}$ to the first position of stimulation at the level of foramen ovale and a further $14 \mathrm{~mm}$ to the second, retrogasserian, position. A difference between the two sites of $17 \mathrm{~mm}$ was however computed by measuring the distance on radiographs. The resulting conduction velocity was then $55 \mathrm{~m} / \mathrm{s}-68 \mathrm{~m} / \mathrm{s}$, according to the method of measuring the distance.

The $\mathbf{M}$-waves were not followed by any response at either site of stimulation. In particular no F-like waves were identified with supramaximal stimuli.

\section{Responses to masseteric nerve stimulation}

When stimulating the masseteric nerve below the zygomatic arch, the masseter M-waves could be always obtained, even though particular care had to be taken in placing the stimulating electrodes close to the nerve in order to minimise the stimulus artifact (fig 3). Mwaves had shorter duration (table 1) than the respective responses obtained from intracranial stimulation. The average latency was $1.65 \mathrm{~ms}(1.4$ $1 \cdot 8$ ), allowing for a conduction velocity of $54 \mathrm{~m} / \mathrm{s}$ in the portion foramen ovale-zygomatic arch.

\section{Findings in patients having a second operation}

Though all had some defect of sensation in the face, only two out of the seven patients who had already undergone trigeminal surgery had clear signs of motor impairment.

Intracranial stimulation revealed definite abnormalities of motor conduction in four cases and borderline values in one. The results for the masseter muscle, which are similar to those for the other masticatory muscles, are summarized in table 2 . An example of temporal muscle responses is given in fig 4 .

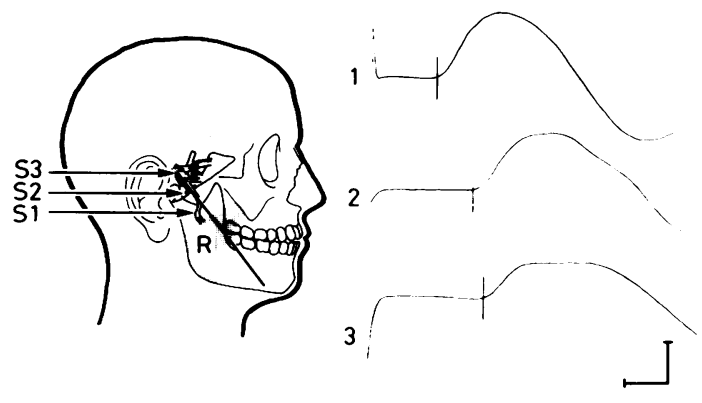

Fig 3 Direct motor responses from different sites of stimulation. $M$-waves recorded from ipsilateral masseter $(R)$ following stimulation of masseteric nerve (1), mandibular nerve (2) and retrogasserian root (3). Onset latencies are indicated by vertical lines.

Calibration: $1 \mathrm{~ms}, 2 \mathrm{mV}$. Note latency increase from 1 to 3 . 

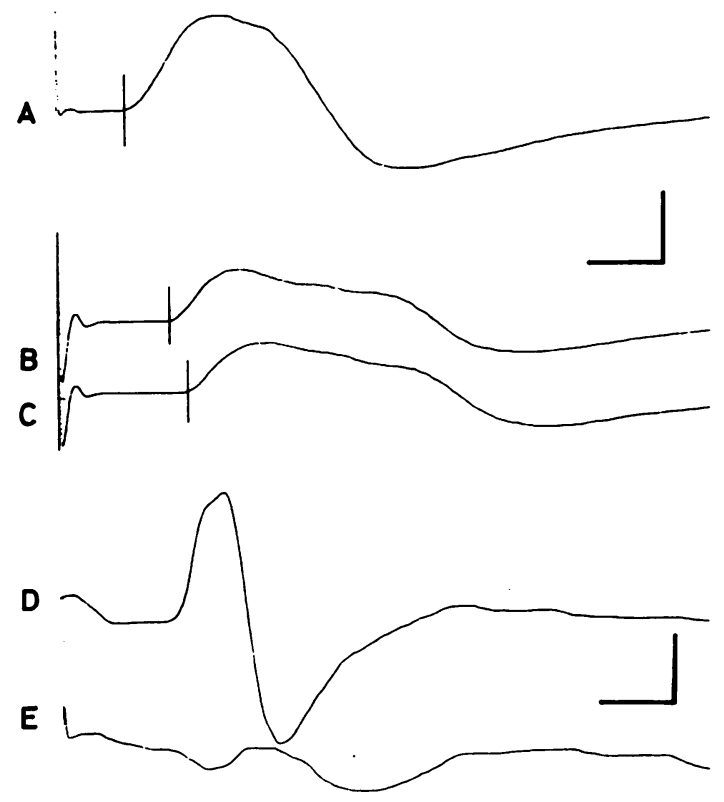

Fig 4 Abnormalities in re-operated subject.

Recordings from temporal muscles. $(A)$ example of normal $M$-wave from stimulation at the level of foramen ovale in normal subject. ( $B, C) M$-waves from stimulation at the level of foramen ovale and of the clivus in re-operated subject.

Onset latencies are indicated by vertical lines.

Calibration $2 \mathrm{~ms}, 2 \mathrm{mV}$.

$D, E$ : jaw-reflex from the normal (D) and operated side (E) in re-operated subject.

Calibration: $5 \mathrm{~ms}, 0.5 \mathrm{mV}$.

Note latency increase of $M$-waves and jaw-reflex in the operated side.

In one patient who had surgical partial root section (case 14), it was impossible to evoke any M-waves with stimuli up to $50 \mathrm{~mA}$ apart from a small response $(3.6 \mathrm{~ms}, 100 \mu \mathrm{V})$ in the digastric muscle. In three patients who had radiofrequency thermocoagulation (cases $4,5,13$ ), there was a marked slowing of conduction velocity: $28-40 \mathrm{~m} / \mathrm{s}$. The distal latencies were increased in case $4(2.9 \mathrm{~ms}$ latency to the masseter and $3 \mathrm{~ms}$ to the temporalis) and in case $13(2.7 \mathrm{~ms}$ to the temporalis). Conduction times were equivocal in case 22. The amplitude of the $\mathbf{M}$-waves was abnormally small in case 5 .

\section{Discussion}

Are the subjects normal?

The experiments were carried out in subjects who may not be regarded as suitable for a study mainly aimed at assessing normal nerve function.

Sub-clinical nerve lesions have been suggested among the possible causes of trigeminal neuralgia, the "idiopathic" label being misleading, particularly by those authors espousing the notion of peripheral aetiology resulting from mechanical factors, such as the pulsatile contact between the internal carotid artery and the ganglion or impingement on the root by vascular loops in the posterior fossa. ${ }^{21} 22$ In fact, strong evidence in favour of pathological changes in primary neurons has been provided following the studies of Beaver $e t a^{23}$ and Kerr. ${ }^{24}$ In addition, the patients were being treated with anticonvulsants which can decrease the conduction velocity in the distal portion of limb nerves. ${ }^{25}$ However, our subjects did not show any neurophysiological abnormality in the three trigeminal divisions, as assessed by the blink reflex to supraorbital and infraorbital stimulation and by the jaw jerk. These facial reflexes have been shown to be normal in patients suffering from "idiopathic" trigeminal neuralgia and who were taking anticonvulsants, and are considered the best means of differentiating essential from symptomatic trigeminal neuralgia. ${ }^{11} 13$

We agree with the hypothesis of a peripheral and mechanical aetiology for the neuralgia, but the common observation of no neurological deficit in the great majority of cases implies that either trigeminal function is protected by a large biological reserve or, as Kerr himself stated, ${ }^{21}$ it is possible that only a few fibres are involved.

Saunders et $\mathrm{l}^{12}$ found fibrillation potentials in the temporal or masseter EMG in seven out of 18 cases of trigeminal neuralgia. However, two of these patients were suspected of lues and multiple sclerosis and the others ranged in age between 74 and 79 years. The finding of denervation potentials never occurred in the present study.

The average age in our case material was 56 years. Changes in the myelin sheath which occur with ageing could only affect nerve conduction to a very small extent in this age group. ${ }^{26}$ The only studies which provide information about a trigeminal motor response at older ages are those measuring the latency of the jaw jerk by Goodwill ${ }^{10}$ and Ongerboer de Visser. ${ }^{13}$ In Goodwill's group the latency of the jaw jerk was the same in subjects younger and older than 40 years, while Ongerboer de Visser and Goor found a $11-12 \%$ increase of latency in subjects aged $50-80$ years in comparison with the $20-50$ age groups. It is impossible to assess the separate contribution of the afferent, central and efferent delays to this latency.

What seems most worth reporting is the fact that the latency of the masseter M-wave to stimulation of the masseteric nerve found in the present study did not exceed the values $(1.3-1.9 \mathrm{~ms})$ reported by Godaux and Desmedt ${ }^{16}$ in a group of normal volunteers in their twenties. 
Findings in "normal" subjects

As expected, stimulation of the mandibular division at the level of the foramen ovale activated all the ipsilateral masticatory muscles from which the recordings were taken. There were no noteworthy differences in the motor fibres directed to the temporal, masseter and digastric muscles, as shown by their threshold and conduction velocity. The M-wave of the anterior belly of the digastric muscle has been recorded for the first time in man. It was similar to the direct responses of the short hand muscles or of the masseter, the only significant difference from the latter being the longer latency, ascribable to the longer conduction distance. We have no direct evidence for the activation of the pterygoids and the mylohyoid, though they could be the generators of the small potentials picked up from the facial derivations. It is possible to exclude activation of the contralateral muscles. This was reported as the result of the stimulation of the trigeminal "dorsal root" in one case of root section by the posterior approach. ${ }^{27}$ These authors attempted intracranial stimulation in that one case only and gave no explanation of the event.

Retrogasserian stimulation also evoked fully developed direct motor responses in most cases, though the needle-electrode was not aimed at the motor root, being presumed to be within the so-called "portio major". Actually, throughout the interval from pons to ganglion the sensory and motor fibres run in a number of rootlets with several anastomoses among the sensory divisions and between sensory and motor rootlets. ${ }^{1}$ Our findings by no means imply that afferent and efferent fibres run intermingled in the trigeminal root. Although the stimulus should remain confined to a relatively small area, owing to the electrode's characteristics, its possible spread cannot be determined precisely. One cannot rely completely upon the subject's report either. The fact that motor threshold progressively increased at the mandibular nerve, V3 and V2 stimulation sites seems to indicate that the motor fibres were progressively more distant from the three structures.

\section{Conduction velocity of trigeminal motor fibres}

The intracranial motor conduction velocity was estimated to be $55-68 \mathrm{~m} / \mathrm{s}$. The short distance and the difficulty of accurate measurement might cast some doubts on the reliability of the velocity values. There were differences of a few millimetres only between the measurements taken from the cannula and from the radiographs, which may nevertheless result in large errors in calculating velocity. On the other hand, the velocity of $54 \mathrm{~m} / \mathrm{s}$ found in the masseteric nerve was slightly lower than the intracranial velocity, which is reasonable. The estimated conduction velocity in the whole portion between clivus and zygomatic arch was
$55-60 \mathrm{~m} / \mathrm{s}$.

Indirect support comes from the latency difference between masseter and digastric $\mathrm{M}$-waves. The distance from the foramen to the anterior belly of the digastric is approximately $40 \mathrm{~mm}$ longer than to the masseter, which results in a $58 \mathrm{~m} / \mathrm{s}$ conduction velocity, the delay being $0.72 \mathrm{~ms}$. We think that this value should be taken as the most reliable, being computed over the longest distance.

McIntyre and Robinson, ${ }^{28}$ proposed a conduction velocity of $100 \mathrm{~m} / \mathrm{s}$, on the basis of the fibre size they measured with light microscopy in the motor root of one necropsy specimen. The largest diameter being 17 $\mu \mathrm{m}$, a conduction speed of $100 \mathrm{~m} / \mathrm{s}$ was calculated by multiplying by a factor of six, according to the method of Hursh. ${ }^{29}$ However, in 1979 Young and Stevens, ${ }^{30}$ by using electron microscopy, were able to determine the overall fibre size spectrum of the human trigeminal motor root. Myelinated fibres presented two main peaks, the larger fibres falling in the $8-14 \mu \mathrm{m}$ range. The ratio between conduction velocity and fibre diameter has not been established in humans, and normative morphological data for muscle nerves are not available in man. ${ }^{31}$ However, a comparison can be drawn with the few data existing on the other human cranial nerves: the diameters of the largest peaks of the nervi accessorius, hypoglossus and facialis are 8-18 $\mu \mathrm{m}^{32} 11-13 \mu \mathrm{m}^{33}$ and 12-15 $\mu \mathrm{m}^{32}$ respectively, the corresponding conduction velocities being $71 \mathrm{~m} / \mathrm{s},{ }^{34} 57 \mathrm{~m} / \mathrm{s}^{34}$ and $45-65 \mathrm{~m} / \mathrm{s}^{35} 36$

The occurrence of an F-like response ${ }^{3738}$ to stimulation of the masseteric nerve has been reported by Fujii $^{39}$ in one third of cases, but was not seen in the present series.

The absence of F-responses to intracranial stimulation could be due to the short conduction distance. Since the site of stimulation could be as far from the motor nucleus as $45 \mathrm{~mm},{ }^{17}$ it would take only $1.5 \mathrm{~ms}$ to an antidromic motor volley travelling at $58 \mathrm{~m} / \mathrm{s}$ to get to the centre and come back. The time needed for the generation of the recurrent action potentials in the axon hillock is not known, though a value of $1 \mathrm{~ms}$ is usually accepted. ${ }^{38}$ If this delay does not exceed 1.5 ms, an F-wave would reach the muscle during the absolute refractory period of muscle fibre, which can last $3 \mathrm{~ms}^{40}$

\section{Findings in re-operated subjects}

The findings in the two patients who had their roots sectioned were clear and anticipated by clinical examination: in one the motor root was spared and in the other it was cut.

Surprisingly, while a masticatory impairment had been noticed in one, there was a remarkable slowing of the intracranial conduction velocity to $28-40 \mathrm{~m} / \mathrm{s}$ in three of the patients who had already undergone 
percutaneous thermocoagulation, while the amplitude was significantly reduced in only one case (see table 2). Thus the neurophysiological data seem to indicate that the myelin sheath was far more affected than the axons. Among the possible causes, the heat produced by the radiofrequency lesion should be taken into account.

The Sweet and Wepsic technique, ${ }^{6}$ is said to be differential in damaging the smaller fibres while sparing the larger ones. Despite the precautions taken in adjusting the position of the coagulating needle and the graded control of temperature, the occurrence of defects of tactile sensation is almost inevitable, while a partial motor root weakness is a transient side effect in $22 \%-43 \%$ of cases. ${ }^{67}$

We found a subclinical impairment of the motor root up to 2 years after the lesion. This means that a stable defect could pass unnoticed in the common evaluation of the side effects of percutaneous radiofrequency thermocoagulation.

A larger number of observations are of course needed. Ideally, the same patients on whom the original recordings were performed should be employed, in the event that a relapse occurs and a further operation is performed.

I am greatly indebted to Dr D Bowsher for his advice. I thank Drs JC Wells, J Miles and A Bainton for their collaboration during the operations and $\mathrm{Mr}$ A Ardrey for his technical assistance.

This work was supported by a grant from the National Research Council of Italy (CNR), Rome.

\section{References}

${ }^{1}$ Gudmundsson K, Rhoton AL, Rushton JG. Detailed anatomy of the intracranial portion of the trigeminal nerve. $J$ Neurosurg 1971;35:592-60.

${ }^{2}$ Leandri M, Parodi CI, Favale E. Early evoked potentials detected from the scalp of man following infraorbital nerve stimulation. Electroencephalogr Clin Neurophysiol 1985;62:99-107.

${ }^{3}$ Cruccu G, Fornarelli M, Inghilleri M, Manfredi M. Reflex and cortical responses to dental stimuli. Ital J Neurol Sci 1983;3:309-15.

${ }^{4}$ Cruccu G, Agostino R, Fornarelli M, Inghilleri M, Manfredi M. Recovery cycle of the masseter inhibitory reflex in man. Neurosci Lett 1984;49:63-8.

${ }^{5}$ Ongerboer de Visser BW. Anatomical and functional organization of reflexes involving the trigeminal system in man: jaw reflex, blink reflex, corneal reflex and exteroceptive suppression. Adv Neurol 1983;39:729-38.

${ }^{6}$ Sweet WH, Wepsic JG. Controlled thermocoagulation of trigeminal ganglion and rootlets for differential destruction of pain fibres. Part 1. Trigeminal neuralgia. J Neurosurg 1974;40:143-56.

${ }^{7}$ Tew JM. Treatment of trigeminal neuralgia by percutaneous rhizotomy. In: Youmans JR, ed. Neurological Surgery Vol 6. Philadelphia: WB Saunders Co,
1982.

${ }^{8}$ Henderson WR. Trigeminal neuralgia: the pain and its treatment. Br Med J 1967;1:7-15.

${ }^{9}$ Morello G, Bianchi M, Migliavacca F. Combined extraintradural rhizotomy for the treatment of trigeminal neuralgia-results in 409 patients. $J$ Neurosurg 1971;34:372-9.

${ }^{10}$ Goodwill CJ. The normal jaw reflex: measurement of the action potential in the masseter muscles. Ann Phys Med 1968;9:183-8.

${ }^{11}$ Kimura J, Rodnitzky RL, Van Allen WM. Electrodiagnostic study of the trigeminal nerve. Orbicularis oculi reflex and masseter reflex in trigeminal neuralgia, paratrigeminal syndrome and other lesions of the trigeminal nerve. Neurology (Minneap) 1970;20:574-83.

${ }^{12}$ Saunders RL, Krout R, Sachs E. Masticator electromyography in trigeminal neuralgia. Neurology (Minneap) $1971 ; 21: 1221-5$

${ }^{13}$ Ongerboer de Visser BW, Goor C. Electromyographic and reflex study in idiopathic and symptomatic trigeminal neuralgias: latency of the jaw and blink reflexes. $J$ Neurol Neurosurg Psychiatry 1974;37:1225-30.

${ }^{14}$ Ferguson IT. Electrical study of jaw and orbicularis oculi reflexes after trigeminal nerve surgery. $J$ Neurol Neurosurg Psychiatry 1978;41:819-23.

${ }^{15}$ Lahuerta J, Lipton S, Miles J. Percutaneus radiofrequency gangliolysis in the treatment of trigeminal neuralgia. Eur Neurol 1985;24:272-5.

${ }^{16}$ Godaux E, Desmedt JE. Human masseter muscle: $\mathrm{H}-$ and tendon reflexes. Arch Neurol 1975;32:229-34.

${ }^{17}$ Delmas A, Pertuiset B. Topometrie Cranio-encephalique chez l'Homme. Paris: Masson, 1957.

${ }^{18}$ Kimura J. Clinical uses of electrically elicited blink reflex. Adv Neurol 1983;39:773-86.

${ }^{19}$ Rakhawy MT, Shehata SH, Badawy ZH. The points of nerve entry and the intramuscular nerve branchings in the human muscles of mastication. Acta Anat 1976;94:609-16.

${ }^{20}$ Cruccu G, Bowsher D. Intracranial stimulation of the trigeminal nerve in man. II. Reflex responses. $J$ Neurol Neurosurg Psychiatry 1986;49:419-427.

${ }^{21}$ Kerr FWL. Evidence for a peripheral etiology of trigeminal neuralgia. $J$ Neurosurg 1967;26:168-74.

${ }^{22}$ Bennett MH, Jannetta PJ. Evoked potentials in trigeminal neuralgia. Neurosurgery 1983;13:732-6.

${ }^{23}$ Beaver DL, Moses HL, Ganote CE. Electron microscopy of the trigeminal ganglion. III. Trigeminal neuralgia. Arch Pathol 1965;79:571-82.

${ }^{24}$ Kerr FWL, Miller RH. The pathology of trigeminal neuralgia. Electron microscopic studies. Arch Neurol 1966;15:308-19.

${ }^{25}$ Geraldini C, Faedda MT, Sideri G. Anticonvulsant therapy and its possible consequences on peripheral nervous system: a neurographic study. Epilepsia 1984; 25:502-5.

${ }^{26}$ Kaeser HE. Nerve conduction velocity measurements. In: Vinken PJ, Bruyn GW, eds, Handbook of Clinical Neurology. Vol 7. Amsterdam: North-Holland 1970: 116-98.

${ }^{27}$ Ley A, Montserrat L, Bacci F, Ley A. Clinical and electrophysiological studies on sensory conduction mediated by the accessory rootlets of the human trigeminal 
nerve. J Neurosurg 1975;42:413-21.

${ }^{28}$ McIntyre AK, Robinson RG. Pathway for the jaw-jerk in man. Brain 1959;82:468-74.

${ }^{29}$ Hursh JB. Conduction velocity and diameter of nerve fibers. Am J Physiol 1939;127:131-9.

${ }^{30}$ Young RF, Stevens R. Unmyelinated axons in the trigeminal motor root of humans and cat. J Comp Neurol 1979;183:205-14.

${ }^{31}$ Stevens JC, Lofgren EP, Dyck PJ. Histometric evaluation of branches of peroneal nerve: technique for combined biopsy of muscle and cutaneous nerve. Brain Res 1973;52:37-59.

${ }^{32}$ Bergstrand 1939, quoted by Kaeser $\left({ }^{26}\right)$.

${ }^{33}$ Heinbecker et al. 1936, quoted by Kaeser $\left({ }^{26}\right)$.

${ }^{34}$ Skorpil V, Zverina E. Conduction velocity in cranial nerve of man. Cesk Neurol 1963;26:152-6.
${ }^{35}$ Kugelberg E. Facial reflexes. Brain 1952;75:385-96.

${ }^{36}$ Trontelj MA, Trontelj JV. Reflex arc of the first component of the human blink reflex: a single motoneurone study. J Neurol Neurosurg Psychiatry 1978;41:538-47.

${ }^{37}$ Magladery JW, McDougal DB. Electrophysiological studies of nerve and reflex activity in normal man. $I$. Identification of certain reflexes in the electromyogram and the conduction velocity in peripheral nerve fibres. Bull Johns Hopkins Hosp 1950;86:265-90.

${ }^{38}$ Kimura J. F-wave determination in nerve conduction studies. In: Desmedt JJ, ed. Adv Neurol 1983;39:961-75.

${ }^{39}$ Fujii $\mathrm{H}$. Electromyographic $\mathrm{F}$ and $\mathrm{H}-\mathrm{F}$-complex responses of jaw closing muscles in man. Arch Oral Biol 1979;24:843-45.

${ }^{40}$ Katz B. Nerve, Muscle and Synapse. New York: McGrawHill, 1966. 